Pakistan Journal of Education

Vol.37, No.1, 2020, 21-44

\title{
Conceptual Content Analysis: Policy Documentation for the Quality of Higher Education in Pakistan
}

\author{
Ayaz Muhammad Khan* \\ Amna Ramzan ${ }^{* * *}$
}

\begin{abstract}
We are living in the age of quality competition, in marketing term, everything in the time is only alive until it sustains its quality. If something is elapsing its quality is it means that is endingits existence from the world gradually. The leading aim of the existing paper was to analyse the content related to quality and quality assurance process of higher education in Pakistan. The paradigm of the research was interpretive paradigm and content analysis with its conceptual design was used to conduct the study. Through purposive sampling, three documents were used as the sample of the study. This investigation was conducted under a developmental approach and various policy documents along with the concerned bodies were used to support the theme of this paper. Multiple sources were used for data analysis, membership categorization analysis for interviews data and keywords in context analysis for document analysis. It was concluded that quality means meeting the predetermined standards and six themes were noted during qualitative analysis. Furthermore, it was assessed that the analyzed quality manuals and, the mechanism with all its operations are measuring the quality of all disciplines with the same brush. By hanging all quality keys at the same grid (Manuals), Teacher Education Programs (TEPs) are indirectly sustained in the standings of quality improvement in Pakistan. It was concluded that quality means meeting the predetermined standards in DAIs in Pakistan.
\end{abstract}

Keywords: quality, quality assurance, teacher education, conceptual content analysis

\footnotetext{
* Director Division of Education: University of Education Lahore Pakistan, Email: ayaz@ue.edu.pk

${ }^{* *}$ PhD. Education Scholar: University of Education Lahore Pakistan, Email: amnaramzan70@gmail.com
} 


\section{Introduction}

We are living in the age of quality competition, in marketing term, everything in the time is only alive until sustains its quality. If something losing its quality is meant to ending its existence from the world gradually (Sallis, 2014). Therefore, to sustain the quality of our products is the guarantee of our existence. Beyond all paradigmatic conflicts in social science research quality is an evolving debate. No doubt total quality management (TQM), zero defect and other quality assurance techniques are hard to implement in social sciences researches(Sallis, 2014) but in terms of system, quality assurance approaches may be implemented to improve the quality of the system or for quality assurance(Hill, Lomas, \& MacGregor, 2003). As per the data retrieved from the Higher Education Commission (HEC) web page the Quality Assurance Agency (QAA) has the key responsibility to maintain the quality of degree-awarding institutions in Pakistan.

By Education for All in world declaration 1990, distinguished that the low quality of education required to enhance and endorsed that education must be more relevant and universally accessible(Pennie, 2001). It was also identified that quality is prerequisite to attain the core goal of equity. But the concept of quality was not accurately developed, quality intended "expanding access alone would be insufficient for education to contribute fully to the development of the individual and society". Later, Dakar Framework for Action sustains that it is the right of every child to get a quality education(Singh \& Singh, 2013).

It is acknowledged that the term quality was "at the heart of education" a decisive determinant or factor of retention, enrolment and achievement ((Blackmur, 2007; Hanushek, 2005). In spite of the fact that this agenda for completing quality education, it didn't accredit any absolute weighting to the different measurements identified. The term quality (as per ISO 9000 series) means the value of everything and everybody in the organization (International Organization for Standardization, 1992). The concept of quality education has contextual and multiple meanings, by taking a critical glance of the literature of quality education maybe assumed "A good quality education is one that provides all learners with capabilities they require to become economically productive, develop sustainable livelihoods, contribute to peaceful and democratic societies and enhance individual wellbeing(Webster, 2017). The learning outcomes that are required vary according to context but at the end of the basic education, the cycle must include threshold levels of literacy and numeracy, basic scientific knowledge and life skills including awareness and prevention of disease. 
Capacity development to improve the quality of teachers and other education stakeholders are crucial throughout this process" but rendering to the teacher education programs the word quality will cover the:

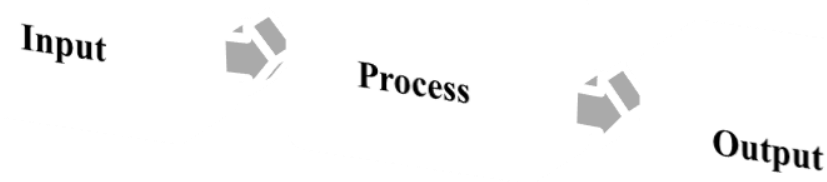

Figure 1: The quality process

Quality is considered an emerging confusing concept in social science research and people perceive quality instinctively in return for different criteria and standards based on their role in marketing, production\& value chain(Singh \& Singh, 2013). Additionally, the concept of quality endures evolving conceptualization according to the quality rues and develops. If we look at the definition of quality, no single explanation is adequate as customer needs are relentlessly changing and the term quality is "situational". A good design for a particular purposeand in eyes of one group of customers may signify a poor design for another set of customers or users(Sharma, Kumar, \& Chawla, 2014).Relying on a single definition is a problem for the quality suppliers in social sciences. It is defined by quality improvement glossary "a subjective term for which each person has his or her definition". David Garvin (1988), Harvard professor in his well-known book "Managing Quality" abridged five principal tactics to define term quality(Garvin, 1988) depicted in the given diagram.

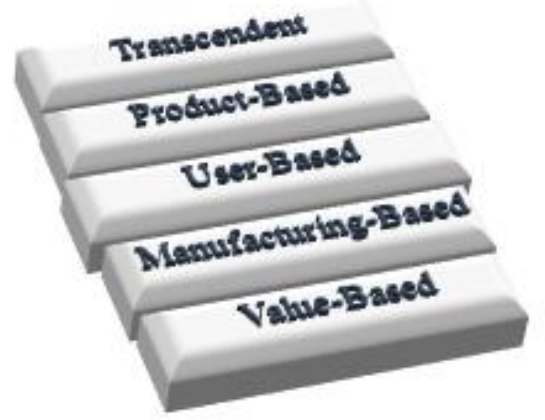

Figure 2: Approaches to quality

Transcendental Quality-- In transcendental view of quality defines 
quality as some abstract perceptual, moral, philosophical and religious entities. This point of view of quality tries to characterize it as far as some unique philosophical, perceptual, good or religious elements. The extraordinary or philosophical point of view seems, by all accounts, to be the establishment from which all other quality viewpoints are at last determined. This methodology sees the quality of an item or administration as an intrinsic trademark that is both outright and allaround unmistakable(Abell, 2013; M. Ahmed, 2012; Batool \& Qureshi, 2007; Dahlgaard-Park, 2015; Dahlgaard, Khanji, \& Kristensen, 2008). Extraordinary quality reviews Plato's idea of magnificence as a "perfect structure." Under this methodology, an item or administration has dependent on its abstract relationship to approximately standards. The capacity to confirm that abstract association must be created through understanding.

Product-Based View of Quality-- This view illustrates a service's or product's quality as measurable, countable grounded on certain attributes or ingredients. Garvin affirmed dessert and mats to show this methodology. Frozen yoghurts, for instance, can be positioned by margarine fat substance, with higher spread fat demonstrating higher quality. Floor coverings can be positioned by the number of bunches per square inch, with a more tightly weave showing higher quality. All things considered, Garvin distinguishes eight different ways or "measurements" that individuals use to assess item quality. These measurements incorporate execution, highlights, trustworthiness, conformance, strong suit, workableness, texture, and saw quality(Fischman, Topper, Silova, Goebel, \& Holloway, 2018; Fonseca, 2015; Garvin, 1988; Hill et al., 2003; Hoyle, 2017). A portion of these measurements is progressively objective, while others are increasingly abstract. Quality is seen as quantifiable and quantifiable qualities or traits.

User-Based Quality-- This method is built on the proposition that quality is "in the eye of the beholder" where the consumer is the manipulator/user. As per this methodology, quality is how much an item or administration fulfils the client's needs, needs, or inclinations. A foundation of Deming's conceptualization of quality-concentrated on the client and recommended that an item can't be a quality item on the off chance that it doesn't meet both express and dormant needs. This is a discerning methodology yet prompts two issues. In the first place, purchaser inclinations change generally, and it is hard to total these inclinations into items with wide intrigue(Krippendorff, 2018; Pennie, 2001; Sharma et al., 2014; Singh \& Singh, 2013). This prompts the decision between a situating technique or a market collection approach 
which attempts to recognize that item quality that addresses the issues of the biggest number of purchasers.

Manufacturing Based Quality Approach--This views of quality as "conformance to requirements." Under this methodology, deviation from the expected client's prerequisites lessens quality. Dissimilar to the client based methodology, the manufacturing-based methodology does not think about the eye of the customers. Or maybe, this methodology looks to unbiasedly gauge how much an item or administration consents to predecided determinations. Garvin distinguishes five kinds of manufacturing forms: venture, work, group, sequential construction system, and nonstop stream. The mechanical production system procedure does not make a difference to interpretation, and any endeavour to consider quality in that setting won't work. Thus, ongoing specialists accept the expression " manufacturing approach" could misdirect into a feeling that this methodology alludes just to make a great many indistinguishable gadgets. Since this methodology goes a long ways past gadgets, thus, presently renamed as "Product based approach(Krippendorff, 2018; Pennie, 2001; Sharma et al., 2014; Singh \& Singh, 2013).

Value-Based View of Quality-- This assumption of quality can be defined "costs and benefits": the more reimbursements overshadow costs, the more services or product upsurges in value. Items or administrations with higher worth appreciate higher quality. Subsequently, the item or administration that executes best may not give the most noteworthy worth thus won't be the most elevated quality. In oversimplified terms, an item showing an abnormal state of conformance and generally low money related expenses would be named a high "esteem" item. The complete expense from a worth based point of view would incorporate both the money related cost of the item and non-financial costs, for example, time, vitality and opportunity costs(Stvilia, Twidale, Smith, \& Gasser, 2005; White \& Marsh, 2006).

Customer-Based Approach of Quality--Quality and excellence are not what you say they are. Quality and excellence are what $\rightarrow$ your customerssay they are. Clients of your items and administrations characterize quality! When was the last time you approached a client for a genuine feeling of the products and enterprises you and your association give? Associations and people that need to excel and succeed (your rivals) are set up to meet routinely with clients and evaluate execution levels, $\rightarrow$ ceaselessly looking for development.

\section{Historical Perspective of Quality}

The roots of quality movement/s maybe smidgen back to medieval in Europe, where the craftsmen started establishing an organization unions 
called "guilds" in the late $13^{\text {th }}$ century. The history of quality maybe categorized in given major paradigms. Early 19th century, industrialized and manufacturing in a world inclined to track this model named craftsmanship. The model named factory system, emphasis on product and service inspection, underway in the Great Britain mid-1750s and cultivated into the Manufacturing Revolution about the early 1800s. American quality process and practices have grown in the 1800 s by way of they were moulded by variations in major production procedures or methods:

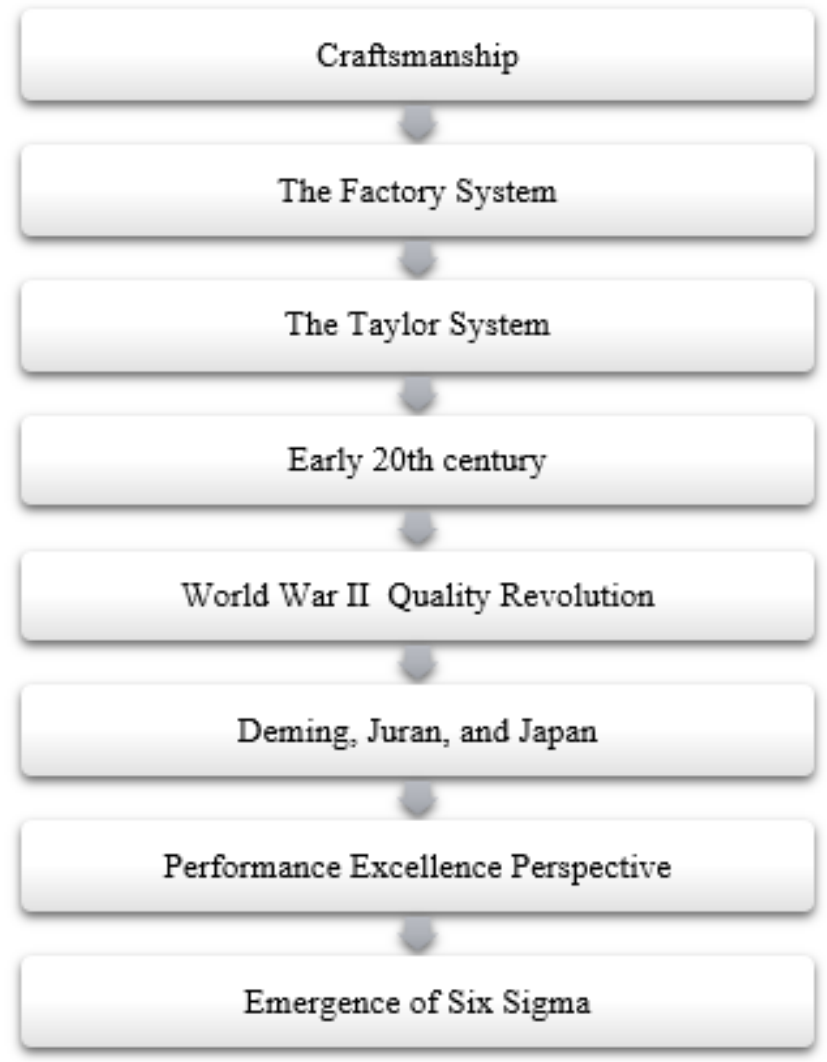

Figure 3: History of quality

Craftsmanship--Producing in the United States would, in general, pursue the craftsmanship model utilized in European nations in the midnineteenth century. In this model, young men took in a talented exchange while filling in as an understudy to an ace, frequently for a long time. Since most skilled workers sold their merchandise nearby, each had a colossal individual stake in gathering clients' requirements for quality. In the event that quality requirements weren't encountered, the skilled worker 
risked losing clients not effectively supplanted. Subsequently, experts kept up a type of quality control by investigating merchandise before the deal.

Factory System View of Quality--A product of the Manufacturing Revolution and establishments in Europe, started to isolate the experts' exchanges into specific assignments named as factory system, This constrained expert to move toward becoming assembly line labourers and constrained retailers to progress toward becoming generation managers, and denoted an underlying decrease in representatives' feeling of strengthening and self-sufficiency in the work environment. Quality in the manufacturing plant framework was guaranteed through the ability of workers enhanced by reviews and additionally examinations. Damaged items were either adjusted or rejected.

The Taylor System- Late in the nineteenth century the United States destitute many from in European convention and received another administration approach created by Frederick W Taylor. His aim was to expand profitability without expanding the quantity of talented skilled workers. He accomplished this by doling out manufacturing plant wanting to particular specialists and by utilizing experts and chiefs, who had been uprooted by the development of production lines, as investigators and supervisors who implemented the designers' arrangements. Taylor's methodology prompted exceptional ascents inefficiency, however, it had critical disadvantages: Workers were deprived of their decreasing force, and the new accentuation on profitability negatively affected quality.

Early 20th century--Manufacturers started to integrate quality measures in a quality field of practices in the mid-twentieth century. The start of the twentieth century denoted the incorporation of "forms" in quality applies. A "procedure" is characterized as a gathering of exercises that takes information, increases the value of it and gives a yield, for example, when a cook changes a heap of fixings into a feast.

World War II-- Subsequent to inflowing World War II on December 1941, the United States ordered enactment to assistance equipment the regular citizen economy to military creation. Around then, military contracts were normally granted to the maker that presented the least offer. Items were examined on conveyance to guarantee conformance to prerequisites. During this period, quality turned into a significant wellbeing issue.

The Quality Revolution--The introduction of all-out the quality was in direct reaction to a quality upset in Japan following World War II in the United States, as actual Japanese manufacturers altered over from transporting military services or products for innermost use to generating citizen and regular merchandise for exchange. 
Deming, Juran \& Japan--The Japanese requested a contribution from inaccessible speakers and organizations, with two American quality experts. As opposed to depending simply on item examination, Japanese producers concentrated on improving every single hierarchical procedure through the general population who utilized them. Accordingly, Japan had the option to deliver higher-quality fares at lower costs, profiting buyers all through the world. American supervisors were commonly uninformed of this pattern, accepting any challenge from the Japanese would eventually come as cost, not quality. Temporarily, Japanese makers started expanding their offer in American markets, causing across the board monetary impacts in the United States, manufacturers started losing a piece of the overall industry, associations started delivering employments abroad, and the economy endured ominous exchange adjusts. In general, the effect on American business shocked the United States energetically.

The American Response-- The U.S. industrialists apprehended onto the supposition about the quality that Japanese accomplishment was price-based, and thus returned to Japanese antagonism with the strategies intended to reducing the price of domestic manufactures or goods costs and limiting imports. No doubt, this fixed nothing to progress American attractiveness in quality. With the passage of time, price war declined and immobile while competition for quality still continued to upsurge.

Beyond Total Quality Total Quality Management (TQM) measured little more than a fad by many American commercial leaders by the end of the 1990s.As the 21st-century starts, the quality movement has ripened. Tague says new quality frameworks have developed past the establishments laid by Juran and Deming, the early Japanese professionals in the field of quality. A few instances of this development: In 2000 the ISO 9000 arrangement of value the executive's measures were updated to expand accentuation on consumer loyalty. Starting in 1995, the Malcolm Baldrige National Quality Award added business results standard to its proportions of candidate achievement. Six Sigma, a strategy created by Motorola to improve its business forms by limiting imperfections, advanced into a hierarchical methodology that accomplished achievements - and critical main concern results. At the point when Motorola got a Baldrige Award in 1988, it imparted its quality practices to other people.

Performance Excellence Perspective All out quality changed the manner in which that associations pondered clients, HR, and assembling and administration forms. From this thought, the idea of TQM has advanced into the idea of execution greatness, which can be characterized as a unified way to covenant with authoritative 
implementation the board that outcomes in the delivery of consistently improving an inducement to clients and associates, adding to hierarchical supportability, improvement of in general authoritative capability and abilities, and) organizational and individual learning.

The Emergence of Six Sigma--It is another way to deal with the quality improvement that reappeared in the late 1990s. It is a clientcentred and a results-situated way to deal with the business improvement that incorporates numerous conventional quality improvement devices and methods that have been tried and approved throughout the years, with the main concern and vital direction that interests to ranking directors, in this manner picking up their help. Six Sigma. Six Sigma $(6 \sigma)$ is a lot of procedures and apparatuses for procedure improvement. It was presented by architect Bill Smith while working at Motorola in 1986.

\section{Quality of Higher Education in Pakistan}

The HEC stimulated the improvement of the higher education framework in the nation with the ultimate reason for overhauling the colleges and degree-granting schools in the nation to be the point of merging of the quality learning in education, research, and advancement. More than quite a long time, the HEC performs a vital and driving job towards developing a knowledge-based economy in Pakistan by apportioning out a number of doctoral scholarships and grants for education abroad consistently.

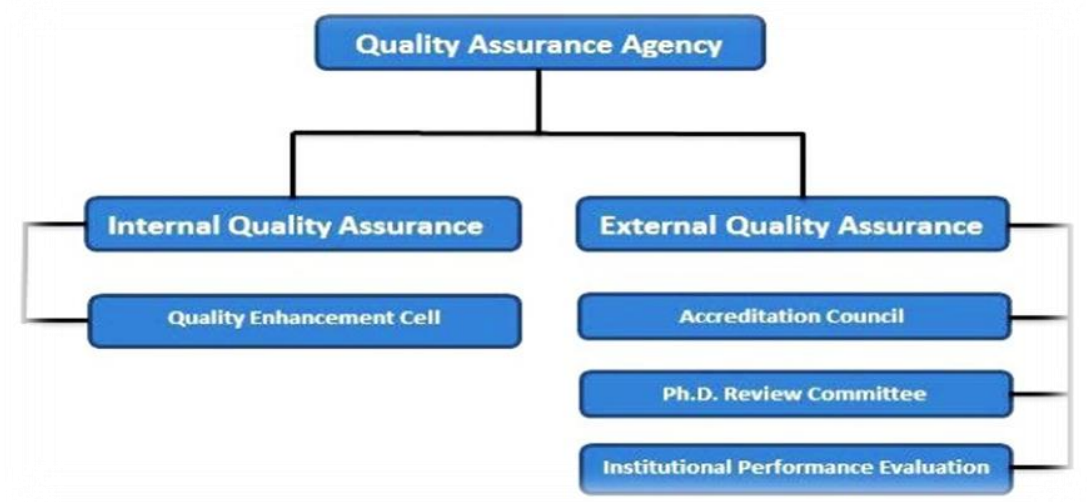

Figure 4: Functions of the QAA \& HEC

In Pakistan standard and quality of higher education especially in teacher education declined considerably. Consequently, in 2002, the 
government has powered the Higher Education Commission. The HEC paved the way to rejuvenate refresh, sustain, authorize, regulate, support and prepare functional the establishments undertaken and operationalized by the various respective universities in an active culture is movable and active movements. As the problem statement indicates, this study was a shred of empirical evidence to analyze and evaluate the reforms in teacher education under the higher education in Pakistan.

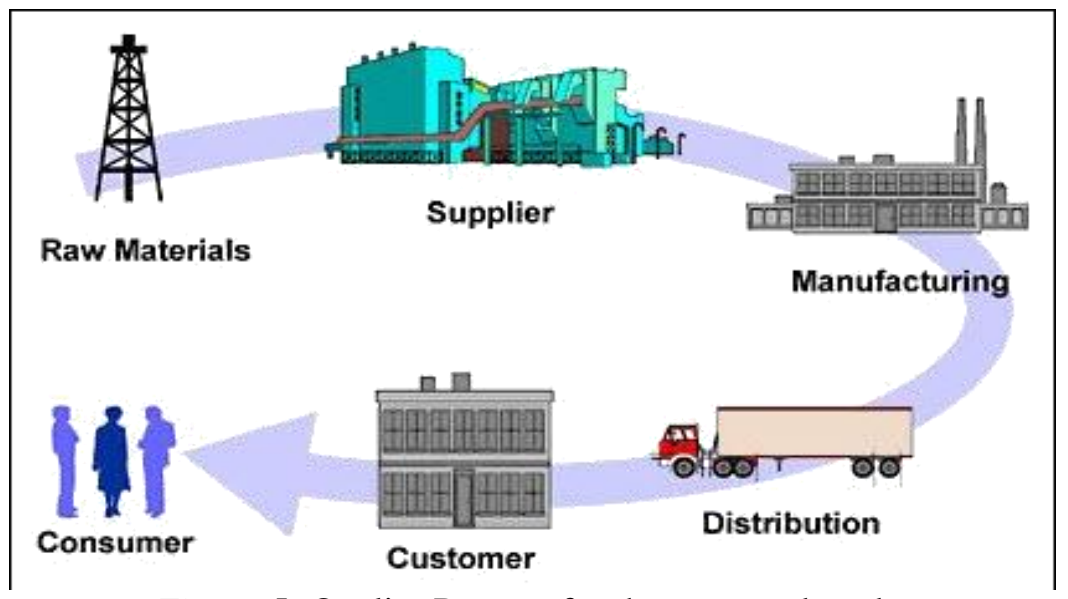

Figure 5: Quality Process for the proposed study

\section{Research Question}

This study was conducted to answer the following research questions:

1. What is the definition of the term "Quality" and Quality Assurance" used in the Manuals published on quality in Pakistan?

2. What is the indicator of quality as per Higher Education Commission manual, NACTE Manual \& QEC Manual?

3. Which quality manual explains the term quality of higher education comprehensively?

4. Is there any need for revisions in the sampled policy documents regarding the conceptualization of the term quality education?

\section{Method}

The study in hands was the yield of an intensive, critical and acute investigation in the field of quality and more specifically quality of teacher education in Pakistan. Historically there is a scarcity of such types of studies(Lloyd, Mete, \& Sathar, 2005), support or add the new elements in existing definitions of the basic terminology as prescribed by 
the encyclopedia, experts, bodies or other related functions deals with defining social sciences terminology. By smearing critical lens, the current study was conducted under the developmental design of research introduced by Creswell (2011). The paradigm of the research was interpretivism and conceptual content analysis design was applied. Content analysis can be defined as a research tool that is used to assess or determine the occurrence of certain concepts, words or themes, within the given prescribed qualitative data (i.e. text) or other material (Krippendorff, 2018). Using the approach of content analysis, the researchers can measure, quantify and analyze the manifestation, concepts, relationships meanings of certain themes, words or concepts(White \& Marsh, 2006). Researchers can mark inferences regarding the messages or meaning within sated in the texts, the writer(s), the spectators, and even the time and culture of immediatein the text(White \& Marsh, 2006).Content analysis is a research method, applied in the design of both qualitative, quantitative, afterthoughts mixed methods of research models or frameworks and pays a wider range of methodical procedures to engender findings in order to put it into context(Neuendorf, 2016). Content analysis can be defined as a rigorous \&systematic approach to examining documents selected or engendered during the course of research (Krippendorff, 2018).

\section{Sample Documents}

Reserving the critical and purposive lens three documents were selected as subject to analyze just the definition of term "Quality" or "Quality Assurance" in Pakistani Higher education system.

1. Quality Assurance Manual for Higher Education in Pakistan(Batool \& Qureshi, 2007)

2. Manual of Accreditation for Teacher Education Institution (NACTE)

3. Higher Education Commission, Self-Assessment Manual for QEC (Quality Enhancement Cell)

\section{Data Analysis}

By using N-Vivo data were analyzed and themes were noted regarding the quality and quality assurance in teacher education. As supported by the literature (Zhang \& Wildemuth, 2009) thematic analysis is a good tool to analyze content or document. Content Analysis (CA) is the process or tool for of studying documents, text or communication artifacts, to analyze or quantifying the presence, relationship and meanings of certain themes, words or concepts (Krippendorff, 2018). CA 
(content analysis) includes pictures, policy documents, the test of different formats, audios and videos which social science researchers use to examine the patterns of communication in a systematic replicable manner (Hopkins \& King, 2010). There are two methods of content analysis advocated by researchers in social sciences research qualitative content analysis and quantitative content analysis (Schreier, 2012). The researchers use systematic reading of documents or observation of artifacts or texts and assigned codes or labels to signpost the presence of concept, interesting, meaningful pieces of content is meant as qualitative content analysis (Mayring, 2004). The terms Quantitative CA acmes the frequency counts of words and objective analysis of these labelled frequencies of words or concepts in a document. Additionally, it inaugurates with an edged research hypothesis with the coding definite procedure before the analysis initiates. In the deductive content, analysis categories are firmly relevant to the researcher's stated hypothesis (Riffe, Lacy, Fico, \& Watson, 2019; Rourke, Anderson, \& development, 2004).

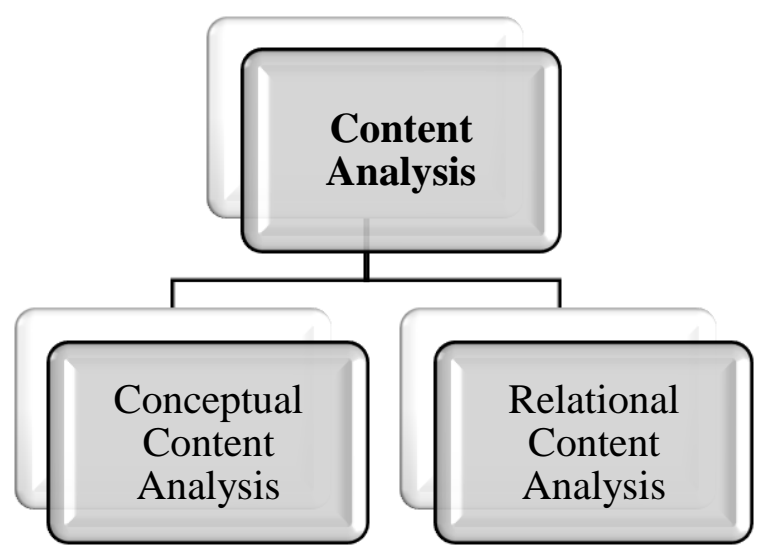

Figure 6: Types of Content Analysis

Content Analysis conducted with two major designs, relational analysis and conceptual analysis. The conceptual content analysis concludes the frequency and existence of concepts in a document/text and relational content analysis progress the conceptual content analysis supplementary by examining and assessing the relationships among codes and concepts concluded from the text (Graneheim \& Lundman, 2004). The Quality Assurance Manual by the Quality Assurance Agency and Standards by the National Accreditation Council for Teacher Education Pakistan was selected for content analysis. Content analysis has similar connotations of conceptual analysis in which concept is chosen for exploration or examination involving quantifying and 
narrating the presence of concepts. The analysis is followed by the steps of thematic analysis and the focus of the researcher is on searching at the presence of the postulated concepts or text (Creswell \& Clark, 2017). The concepts may be searched implicitly or explicitly, the explicit meanings are calm to coding for implicit concepts and determining their nature of implication is difficult by the requirement to base findings on a somewhat idiosyncratic system. The conceptual content analysis method begins with determining research propositions and questions and the process of coding is followed by selective reduction (Mayring, 2014). By the process of reducing the text into categories containing a word, phrases, and research aim are to focus on, coding, explicit words and patterns considered indicative as a research question. The current study was analyzed using the given steps of conceptual content analysis:
A. Determine the level of content analysis
B. Decide the concepts for coding
C. Assess the frequency of decided codes
D. Distinction among concepts
E. Develop rules of Coding
F. Irrelevant information decision
G. Code \& texts
H. Result reporting

\section{Conceptual Content Analysis}

By projecting N-Vivo-12 SA-Manual was primed and analyzed. Seven themes were noted and depicted (Figure.) concerning the quality of TEPs in Pakistan. As buttressed by the great support of literature available on qualitative data analysis (Krippendorff, 2018; Neuendorf, 2016; Riffe et al., 2019; Zhang \& Wildemuth, 2009) thematic analysis technique considered an upright tool to dig out content or document. The manual published by HEC Pakistan itemized the term quality, with its process and principle. The evaluation system (internal \& external) and its criteria in Pakistan has been specified. Comprised of 113 pages of SAmanual contain six areas and an extra part termed appendixes. The first area talks about the presentation of quality confirmation and the standards of the quality affirmation process and procedure. The second segment manages quality confirmation in advanced education in Pakistan established by HEC of Pakistan. The QAA is likewise recorded in this area with its forces, capacities and obligations. Area three named effective ways of thinking of quality confirmation and QA structure has been examined in the fourth segment of the quality manual by HEC. Segment four and fifth is a significant area which signs the quality 
affirmation structure and the assessment framework directed by the QAA as endorsed by the HEC of Pakistan. To wrap things up six-area examine the future prophecy for the quality confirmation in HEIs. Quality confirmation QA agency was set up beneath the umbrella of the HEC of Pakistan characterizes the quality term: The path through which the foundations can guarantee the assurance and certainty, principles, qualities and quality of its arrangements in the terms of training are being continued and improved" The chose to record in this examination was anticipated and broke down by utilizing N-Vivo and depicted word-three was created dependent on the information on the word quality. By using $\mathrm{N}$-Vivo data was analyses and themes were noted regarding the quality and quality assurance in teacher education. As supported by the literature (Zhang \& Wildemuth, 2009) thematic analysis is a good tool to analyses a content or document.

Quality \& Quality Assurance by Higher Education Commission--the manual published by HEC Pakistan signpost the quality, its process, principle, its internal and external evaluation system and criteria for the evaluation of quality in Pakistan. Consisted of 113 pages this manual contains six sections and an additional part named appendixes. $1^{\text {st }}$ section discusses the introduction of quality, quality assurance and the principles of the quality assurance process. $2^{\text {nd }}$ section deals with quality assurance in higher education in Pakistan constituted by HEC of Pakistan. QAA is also documented in this section with its powers, functions and duties. Section three named topical notions of quality assurance and quality assurance framework has been discussed in the $4^{\text {th }}$ section of the quality manual by Higher Education Commission. Section four and five are very important sections which signpost the quality assurance framework and the evaluation system conducted by the Quality Assurance Agency as prescribed by the HEC of Pakistan. Last but not least six-section discuss the future vision for the quality assurance in Higher Education. Quality assurance Agency was established under the umbrella of the HEC of Pakistan defines the quality term:

"The means by which an institution can guarantee with confidence and certainty, that the standards and quality of its educational provisions are being maintained and enhanced"

The selected three documents in this study were projected and analyzed by using N-Vivo and given word three was developed based on the data on the term quality.

National Accreditation Council for Teacher Education in Pakistan (NACTE)--the manual published by National Accreditation Council for 
Teacher Education in Pakistan. Manual has not defined quality in specifically but its take the quality as predetermined standards:

"Accreditation of teacher education is a process of quality assurance whereby an institution or program evaluates itself, is evaluated by a third party and develops a plan to improve concerning pre-determined standards. As a result of this process, an institution is awarded a certificate that states its current status and testifies to its commitment for continuous improvement concerning the predetermined standards".

The standards given by the National Accreditation Council for Teacher Education in Pakistan are seven and depicted in the given figure:

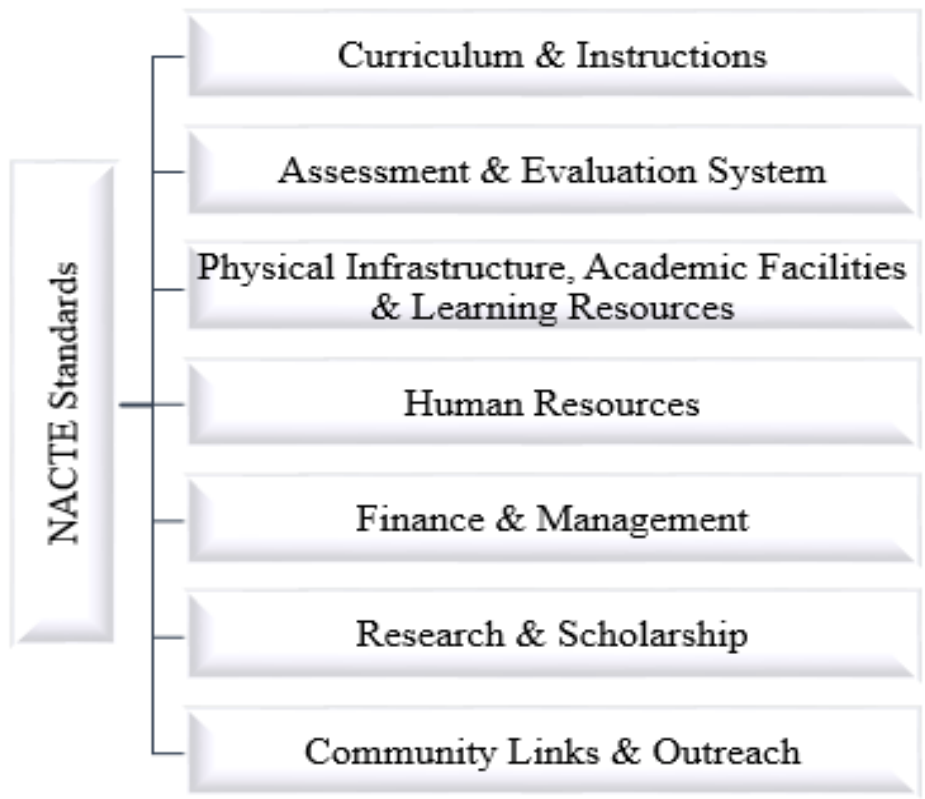

Figure 7: Quality of TEPs by NACTE

Quality Enhancement Cell and Quality--QEC road map did under the prescribed criteria illustrated by this manual named Higher Education Commission Self-Assessment Manual prepared by Professor Dr Abdul Raouf. This analysed manual illustrate us the meaning of quality: 


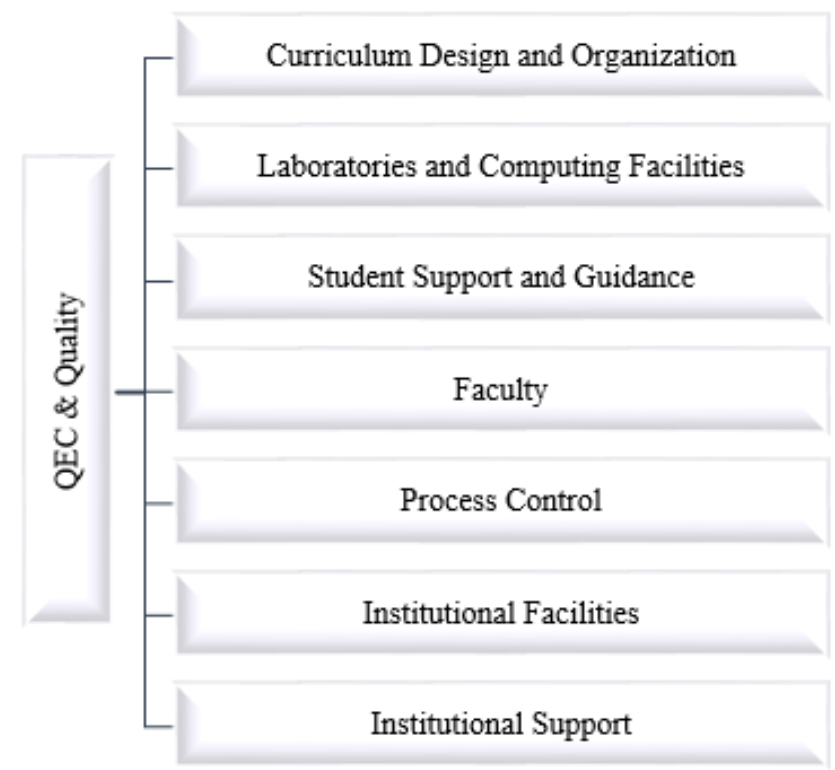

Figure 8: Quality by QEC

It was concluded that the three analyzed documented by Higher Education Commission, National Accreditation Council for Teacher Education Pakistan and Quality Enhancement Cell. All levels of quality measured by this study are similar except the planning process and products. The HEC manual is mainly discussing the quality as input phased, the NACTE manual assumes quality as a sound process phase and finally, the QEC manual suppresses its meaning of quality in the terms of internal system soundness. The after and before quality in the selected was used much time and depicted in the given figure: 


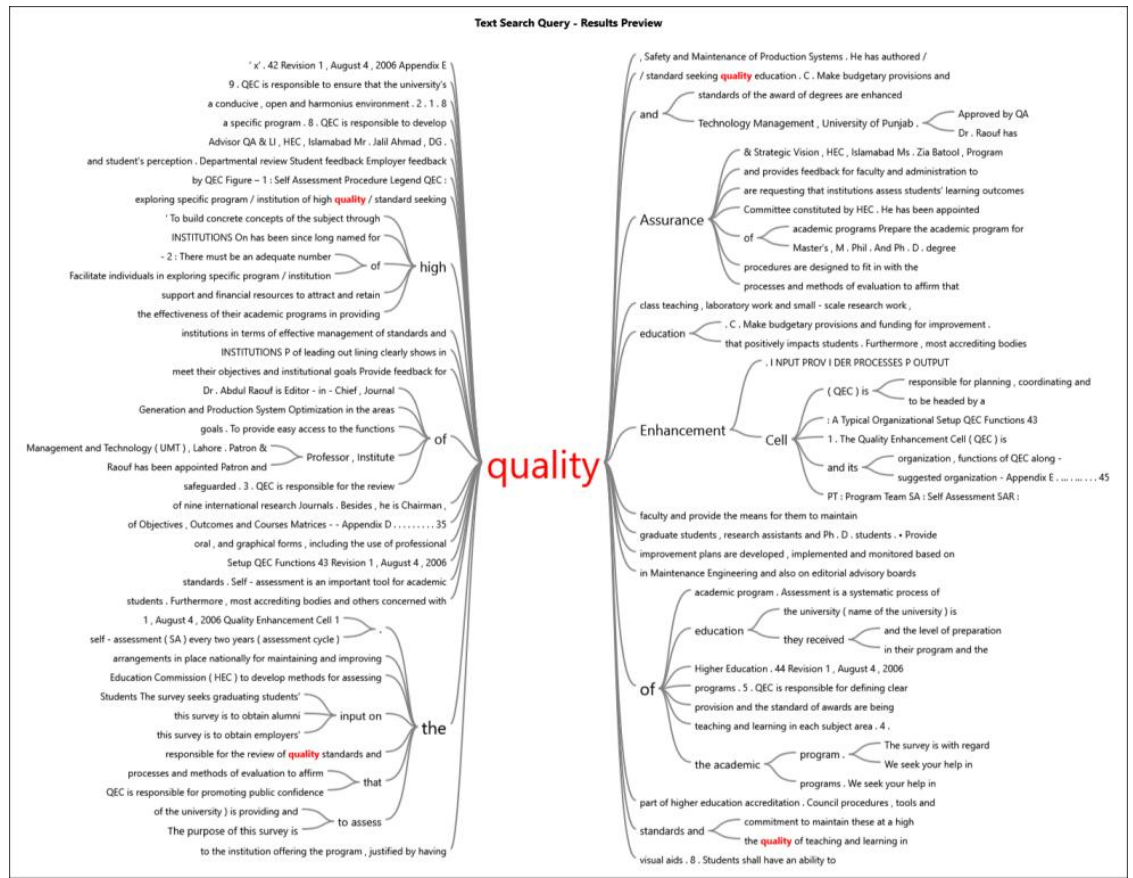

Figure 9: Tree Chart

The given hierarchy chart also depicted the significance of each manual in defining the term quality and quality assurance in Pakistan. Although the output from N-Vivo support that the Higher Education Commission Manual is heavily concerned with the term quality and quality assurance.

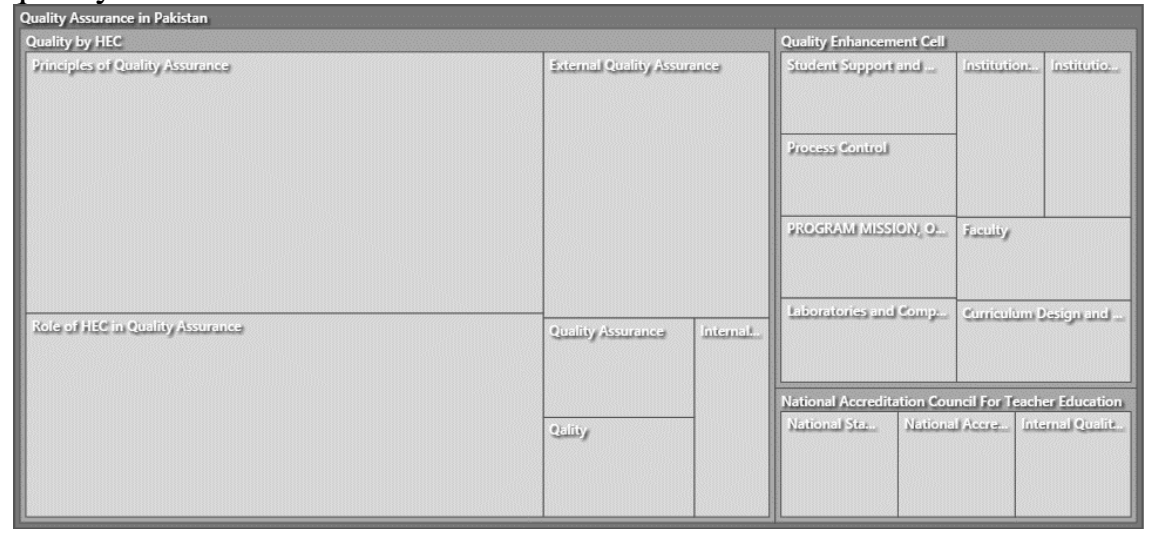

Figure 10: Significance of the themes 
The given project map also graphical representing the used themes and categories of term quality used in the manual/s.

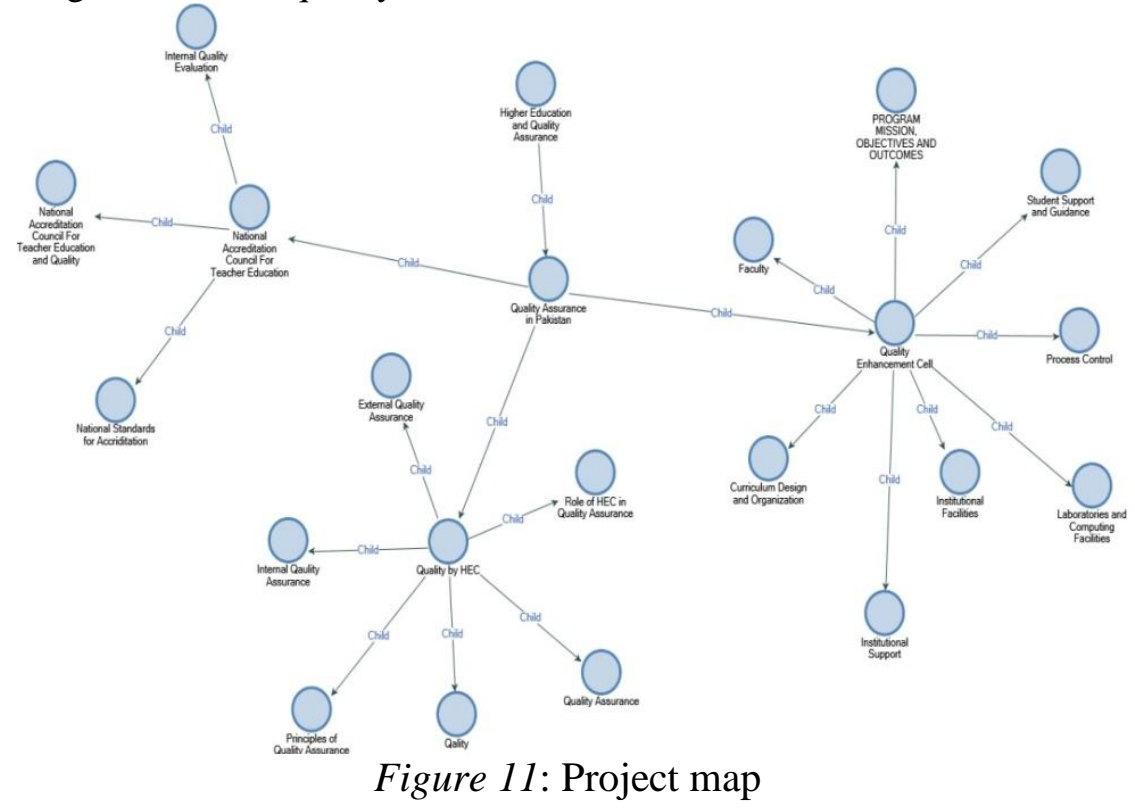

\section{Conclusion and Implications}

While analyzing the QEC manual it was concluded that rules documented by HEC, QAA and QEC gradually for TE Pakistan are well established by adding all indicators of quality but it's a general form of quality indicators. All indicators of quality dignified in the existing study were similar except "planning process and products" that was unique for this manual. This manual was mainly deliberating the term quality process at the input phase; however the aims of manual dons quality as a healthy process. To end with, the manual conquers the meaning and concepts of quality in especially in the terms of internal trustworthiness of the system or organization. The results depicted in the analysis section concluded the implication of the SA manual in describing, explaining and operationalizing the term "quality" \& "quality assurance" of DAIs in Pakistan. The SA-Manual is profoundly alarmed with programs quality and the term quality and quality assurance in various disciplines. It was also explored while searching the SA-Manual that the documentation by the HEC and QEC for quality assurance of DAIs and HEIs in Pakistan is outdate (Abiodullah, Shakoor, \& Farrukh, 2017; Ameen, 2007; Arif \& Ilyas, 2013; Asim, Shah, \& Studies, 2014). The establishment once setup the standards and implemented in the filed by QAA internal and 
external mechanism, after passing 18 to 20 years stills evaluating and sustain the quality practices with the same instrument. HEC \& QAA establishments must renew these standards by the comparisons, metaanalysis and third party involvement. There should be open access for academic researchers to pass out theories in this regard. The first concluded themes were curriculum organization \& design that is considered a major indicator of quality improvement. The SA- manual defines and measures these indicators by using the questionnaire under the quantitative mechanism of QECs in all DAIs in Pakistan. From the glance of literature review, numerous studies have been conducted to explore the indicators of quality assurance and it was noted the quality curriculum has a significant role in improving the quality of education (AHMED, 2012). Based on the above theoretical and empirical argument it was concluded that quality curriculum plays a vital role in the overall quality of the educational institution. The second theme noted as Facilities offered by the DAIs to their students, faculty and other person has an effective part in branding the quality of any program especially in teacher education finance and facilities has a key role in enhancing its quality (Abiodullah et al., 2017; Ahmed, 2012; AHMED, 2012; Ali \& Sciences, 2011; Arif \& Ilyas, 2013; Asim et al., 2014). As per the stated quality parameter for an educational institution, Students support and guidance services are a critical indicator, as it seems as customer stratification. The customer satisfaction is the foremost factor in improving the quality of service (Fonseca, 2015; Hoyle, 2017).Faculty with its high moral, qualification and professional skills affirmed (Khan, Saeed, \& Research, 2009; Saeed \& Research, 2007) a very decisive measure in sustain the quality of all level of education. The SA-manual has also listed this standard and measures it in the process of SAR. Institutional support is the second last factor explored in the SA-manual. The last but not least Process control, it's a technique of monitoring, improving and sustaining the level of quality of a DAIs reported and operationalized by SA-manual. Process control techniques were always considered a key factor in the quality improvement system (Batool \& Qureshi, 2007; Fonseca, 2015; Hoyle, 2017). It was concluded on the basis of above-discussed results of the study numerous factors were missed in the SA-manual on the other side the framed manual need renewal to add the emerging needs in the form of standards. In the contrast, the DAIs being measured under these standards would ultimately lose their quality competition or by following the footprints of history we are failed in branding the quality education system. Based on the above discussion of the results in this study it was concluded that numerous factors and indicators of quality were missed in the SA-manual 
on the other side the framed manual need renewal to add the emerging needs in the form of standards. On 11 August 2006, the revised manual for QECs (SA-Manual) was a milestone value. But it is observed that after passing 15 years there were no new standards was add nor existing was revised or assessed. All DAIs yet meeting the outdated standards, in $21^{\text {st }}$ globally we have faced numerous changes in the systems. Our needs, priorities, challenges, problems have been changes serval times, but our parameters for the quality of DAIs same settled in 2006. All the tools used in SA-Manual of QEC are outdated rather they measuring process level quality effectively but limited in scope the up to date indicators were missed since 2006 there was no revision made by policymakers or competent authorities. Sum up remarks are the limited and restricted scope of the manual being enforce by QAA and HEC respectively. There was an alarming \& growing itinerary was observed that the quality is changing with the passage of time but the concerned establishments didn't revise its perform/s from the time being enforced. There was an appreciation in standing value and demands of academic \& professional disciplines in Pakistan uninterruptedly being censored by HEC, QAA and DAIs respectively. However, a serious concentration in the area of quality definition, indicators needs and dimensions is vital to imposts new parameters. Mostly restricted dimensions of quantity assurance, totally overlooking by authorities and this quality revolution may be projected by applying both (Top-down \& Bottom-up) approach of change. To boost a change in the pre-established standards is a very crucial step but it's vital to competitive the international brands of HEIs globally. At the $1^{\text {st }}$ phase, HEC and DAIs should endorse the academic scholars to empirically and theoretically assess these standards. Especially the standards for Teacher profession needs to change in this way nation can inject quality teacher for the purpose to prepare the quality future. The already data submitted by DAIs to QAA cells need a meta-analysis in this way the existing and recorded difference of quality can be assessed to the road a new map for quality assurance. Comprehensively the SA-Manual is effectively mearing the quality but limited in scope needs to add current standards. We may benchmark the best practice for quality improvement but the QAA and QEC restricted and limited criteria is a briar in this regard. This should be solved by policymakers on an urgent basis, in contrast, we would be the nation of the stone era and mapping our rows blindly. For acknowledging it was a qualitative and contextual biased investigation the validity and trustworthiness is the limitation of this research. There should be serious efforts by HEC and QAA for healthy research culture for evaluating the settled quality standards and third party involvement is the best way in 
this regard. HEC must focus the powers and the working process by QAA, the internal and external quality monitoring bodies must benchmark new standards and pilot in the DAIs. The HEC should measure and operationalized a mechanism for the rate of return analysis along with market value, supply and demand analysis on the disciplinebasis. Comprehensively the analysed SA-Manual is effectively mearing the quality but limited in scope needs to add current standards. 


\section{References}

Abell, S. K. (2013). Research on science teacher knowledge Handbook of Research on Science Education (pp. 1119-1164): Routledge.

Abiodullah, M., Shakoor, U., \& Farrukh, I. A. J. J. o. E. R. (2017). Global Changes and Improving Teacher Education Institutions in Pakistan. 20(2), 113-126.

Ahmed, M. (2012). Factors affecting initial teacher education in Pakistan: Historical analysis of policy network. International Journal of Humanities and Social Science, 13(2), 104-113.

AHMED, S. N. (2012). Quality in teacher education: A situational analysis of quality assurance strategies of teacher education institutions in Pakistan. HAMDARD UNIVERSITY KARACHI.

Ali, \& Sciences, S. (2011). Understanding how practices of teacher education in Pakistan compare with the popular theories and theories and narrative of reform of teacher education in international context. 1(8), 208.

Ameen, K. (2007). Issues of quality assurance (QA) in LIS higher education in Pakistan. Paper presented at the World Library and Information Congress.

Arif, S., \& Ilyas, M. J. Q. A. i. E. (2013). Quality of work-life model for teachers of private universities in Pakistan.

Asim, M., Shah, S, \& Studies, A. (2014). Educational System in British India and its Socio-Political Impacts on Pakistani Society. 7(1), 87.

Batool, Z., \& Qureshi, R. H. (2007). Quality assurance manual for higher education in Pakistan. Higher Education Commission, Pakistan.

Blackmur, D. (2007). A critical analysis of the UNESCO/OECD guidelines for quality provision of cross-border higher education. Quality in Higher Education, 13(2), 117-130.

Creswell, J. W., \& Clark, V. L. P. (2017). Designing and conducting mixed methods research: Sage publications.

Dahlgaard-Park, S. M. (2015). The SAGE encyclopedia of quality and the service economy: SAGE Publications.

Dahlgaard, J. J., Khanji, G. K., \& Kristensen, K. (2008). Fundamentals of total quality management: Routledge. 
Fischman, G. E., Topper, A. M., Silova, I., Goebel, J., \& Holloway, J. L. (2018). Examining the influence of international large-scale assessments on national education policies. Journal of education policy, 1-30.

Fonseca, L. M. (2015). From Quality Gurus and TQM to ISO 9001: 2015: a review of several quality paths. International Journal for Quality Research (IJQR), 9(1), 167-180.

Garvin, D. A. (1988). Managing quality: The strategic and competitive edge: Simon and Schuster.

Graneheim, U. H., \& Lundman, B. J. N. e. t. (2004). Qualitative content analysis in nursing research: concepts, procedures and measures to achieve trustworthiness. 24(2), 105-112.

Hanushek, E. A. (2005). Economic outcomes and school quality (Vol. 4): International Institute for Educational Planning Paris.

Hill, Y., Lomas, L., \& MacGregor, J. (2003). Students' perceptions of quality in higher education. Quality Assurance in Education, 11(1), $15-20$.

Hopkins, D. J., \& King, G. J. A. J. o. P. S. (2010). A method of automated nonparametric content analysis for social science. 54(1), 229-247.

Hoyle, D. (2017). ISO 9000 Quality Systems Handbook-updated for the ISO 9001: 2015 standard: Increasing the Quality of an Organization's Outputs: Routledge.

Khan, S. H., Saeed, M. J. B. o. E., \& Research. (2009). Effectiveness of Pre-service Teacher Education Programme (B. Ed) in Pakistan: Perceptions of Graduates and their Supervisors'. 31(1), 83-98.

Krippendorff, K. (2018). Content analysis: An introduction to its methodology: Sage publications.

Lloyd, C. B., Mete, C., \& Sathar, Z. A. (2005). The effect of gender differences in primary school access, type, and quality on the decision to enroll in rural Pakistan. Economic Development and Cultural Change, 53(3), 685-710.

Mayring, P. (2014). Qualitative content analysis: theoretical foundation, basic procedures and software solution.

Mayring, P. J. A. c. t. q. r. (2004). Qualitative content analysis. 1, 159-176.

Neuendorf, K. A. (2016). The content analysis guidebook: Sage. 
Pennie, I. (2001). Managing quality in higher education: An international perspective on institutional assessment and change. Quality assurance in education.

Riffe, D., Lacy, S., Fico, F., \& Watson, B. (2019). Analyzing media messages: Using Quantitative Content Analysis in Research: Routledge.

Rourke, L., Anderson, T. J. E. t. r., \& development. (2004). Validity in quantitative content analysis. 52(1), 5.

Saeed, M. J. B. o. E., \& Research. (2007). Education System of Pakistan and the UK: Comparisons in Context to Inter-provincial and Intercountries Reflections. 29(2), 43-57.

Sallis, E. (2014). Total quality management in education: Routledge.

Schreier, M. (2012). Qualitative content analysis in practice: Sage publications.

Sharma, M. Y., Kumar, M., \& Chawla, M. (2014). Refining The Defination of the term Bottom of Pyramid. International Research Journal of Management Sociology \& Humanity (IRJMSH), 5(5), 190-212.

Singh, A., \& Singh, R. (2013). Assuring Software Quality using data mining methodology: A literature study. Paper presented at the 2013 International Conference on Information Systems and Computer Networks.

Stvilia, B., Twidale, M. B., Smith, L. C., \& Gasser, L. (2005). Assessing Information Quality of a Community-Based Encyclopedia. ICIQ, 5, 442-454.

Webster, R. S. (2017). Education or quality of teaching? Implications for Australian democracy. Australian Journal of Teacher Education, 42(9), 4.

White, M. D., \& Marsh, E. E. (2006). Content analysis: A flexible methodology. Library Trends, 55(1), 22-45.

Zhang, Y., \& Wildemuth, B. M. (2009). Qualitative analysis of content. Applications of social research methods to questions in information and library science, 308, 319.

\section{Citation of this Article:}

Khan, A. M., \& Ramzan, A. (2020). Conceptual content analysis: Policy documentation for the quality of higher education in Pakistan. Pakistan Journal of Education, 37 (1), 21-44. 